\title{
Inflammatory Biomarkers Status and Liver Enzymes Among Hyperuricemia Patients in Gaza Strip
}

\author{
Asmaa A Hejazi ${ }^{1}$, Ahmad M Tabash ${ }^{1}$, Wesam M Afana ${ }^{2}$ and Ayman M Abu Mustafa ${ }^{3 *}$ \\ ${ }^{1}$ El Najar Hospital, Ministry of Health, Gaza Strip, Palestine \\ ${ }^{2}$ European Gaza Hospital, Ministry of Health, Gaza Strip, Palestine \\ ${ }^{3}$ Palestine College of Nursing, Khan Younis, Gaza Strip, Palestine
}

*Corresponding author: Ayman M Abu Mustafa, Palestine College of Nursing, Khan Younis, Gaza Strip, Palestine, Email: aymanayman20092009@hotmail.com.

\begin{abstract}
Background: The significance of hyperuricemia as a risk factor of incidence of myocardial infarction has been a debate for recent decades. However, Hyperuricemia has been shown to predict the development of heart failure, elevated in weight, hyper-insulinemia of secondary hypertension. Several studies have demonstrated that hyperuricemia is also associated with elevated inflammatory biomarkers levels and development of nonalcoholic fatty liver disease (NAFLD). The aims of the present study were to assess inflammatory biomarkers status and liver enzymes among hyperuricemia patients in Gaza Strip

Materials and Methods: A case-control study has been conducted on 70 subjects with hyperuricemia and 70 healthy subjects with normal uric acid as control aged between 41-70 years. Erythrocyte sedimentation rate (ESR), C - reactive protein (CRP), complement 3 (C3), ferritin, fibrinogen and liver enzymes were measured.

Results: The results pointed out the average levels of ESR, CRP, C3, ferritin, fibrinogen AST and ALT were significantly higher in cases compared to controls. Pearson correlation showed that a positive significant correlation between uric acid and CRP $(r=0.656, P<0.001)$, Fibrinogen ( $r=0.784$, $\mathrm{P}<0.001)$, Ferritin $(\mathrm{r}=0.939$, $\mathrm{P}<0.001)$, ESR $(\mathrm{r}=0.89, \mathrm{P}<0.001)$, ALT $(\mathrm{r}=0.886, \mathrm{P}<0.001)$, AST $(\mathrm{r}=0.844, \mathrm{P}<0.001)$.

Conclusion: Hyperuricemia should be treated because it induces an inflammatory reaction and increases liver enzymess disorder. both hyperuricemia and dyslipidemia will enhance the risk for heart failure. In brief, new strategic management must be developed in order to decrease hyperuricemia among adult.
\end{abstract}

Keywords: Inflammatory biomarkers; Liver enzymes; Hyperuricemia; Gaza Strip

\section{Introduction}

Uric acid is the end product of nucleic acid metabolism in humans and is generated by the action of the enzymes, xanthine oxidase (XO), that catalyzes the last two steps of uric acid conversion: hypoxanthine to xanthine and from xanthine to uric acid [1]. hyperuricemia associated with gouty arthritis (gout) and it is a condition characterized by swollen and hot joints caused by recurrent inflammatory arthritis [2]. The prevalence of hyperuricemia is progressively increasing and considers globularly disease associated with gender and age which leads to uric acid crystal deposits in joints, renal and other tissues and causes a lot of complications [3-5]. Recently, Epidemiological data support gout has been linked to heart disease [6-8]. On the other hands, several studies illustrated that hyperuricemia is the precursors of metabolic syndrome and cardiovascular diseases additionally to peripheral vascular disease and preeclampsia, and renal disease [3, 9-11]. Recent studies on hyperuricemia showed that uric acid crystal-induced inflammation is essential to developing system failure [1,12]. In this study, we investigated the relation of elevated uric acid with inflammatory biomarkers status and liver enzymes among hyperuricemia patients in Gaza Strip.

\section{Materials and Methods}

\section{Study population and experimental design}

Study design and samples: The present study is a case-control study. A total of 140 male. According to the present study were 
divided into 2 categories: group I (70 hyperuricemia male patients) and group II (70 healthy individuals of the same population matched for age were used as a control group). The study was conducted by using collecting research data in the main public hospitals in Gaza strip: Nasser Hospital, European Hospital, El-Shifa Hospital and A l- Najar Hospital. The study data was collected during the period of June 2018 to April 2019.

\section{Inclusion criteria}

Inclusion criteria were between 41-70 years of age who had high uric acid.

\section{Exclusion criteria}

Exclusion criteria were patients with a history of smoke use, hypertension, diabetes mellitus, a cardiovascular disease, myeloproliferative disorder, in therapy with cytotoxic drugs, renal or hepatic disorders and those on antigout therapy, the individuals who were less than 41 years and more than 70 years.

\section{Ethical considerations and permissions}

Consent form to participate in the study was obtained from participants and freely participates in the study. Every participant had been provided with a full explanation of the intended study.

\section{Data collection}

An interview was used for filling in questionnaires. All interviews were conducted face to face by the researchers.

\section{Blood collection}

All blood samples were collected in coagulation, a lavender top tube (EDTA) and serum was taken from participants and sent to the laboratory for analysis. Ferritin concentration was determined by enzymes immunoassay (ELISA) [13]. C3 was measured by using immune diffusion plates (FAR Ven Fermi, 12-Italy) as described by the manufacturer. An amount of serum was placed in the agarose well containing a mono-specific antibody. The serum spreads in the agarose and the contained antigen forms an immune complex with the antibody. A precipitation rings whose dimension is proportional to the concentration of protein in the serum was formed. Sample precipitation diameter was measured, and the reference value table was used to read the concentration of the protein [14]. EDTA tube was collected and tested quickly for ESR while coagulation tube for fibrinogen. Hemolyzed sample is rejected, and sample tubes were allowed to reach room temperature $\left(15-30{ }^{\circ} \mathrm{C}\right)$ before performing the assay. CRP test was measured using a latex test [15].

Expected values for CRP: Presence of agglutination indicates a level of CRP in the sample equal or $>6 \mathrm{mg} / \mathrm{l}$. The lack of agglutination indicates a CRP level $<6 \mathrm{mg} / \mathrm{l}$ in the sample. Expected Values for serum C3 concentrations: 50-120mg/dl. Expected Values for plasma fibrinogen concentrations:200-400mg/dl. Expected Values for ferritin: 16-220ng/ml. Expected Values for ESR $<20 \mathrm{~mm} 3 / \mathrm{hr}$.

\section{Statistical analysis}

Data were analyzed using SPSS version 23. Chi-square $\left(\chi^{2}\right)$ was necessary to compare the relationship between categorical variables, independent sample t-test (two-tailed) was done to assess the differences between case and control and Interrelationships between baseline variables and uric acid were assessed by Pearson's correlation coefficient test. The values in tables were presented as mean \pm standard deviation otherwise noted. P-value of $<0.05$ was considered statistically significant.

\section{Results}

\section{Distribution of studied sample according to socio- demographic data}

The results showed that there are no significant differences between cases and controls group regarding age, employment \& marital status, education levels $(\mathrm{P}>0.05)$. These results indicated statistically no significant differences among groups in sociodemographic characteristics studied that indicate good matching between groups.

\section{Distribution of inflammatory biomarker and liver enzymes among cases and controls}

The Table 1 shows the distribution inflammatory biomarker and liver enzymes among cases and controls. The results showed that there are higher statistically significant in cases compared to controls for CRP ( $7 \pm 1.81$ vs $4 \pm 0.94 \mathrm{mg} / \mathrm{dl}$; $\mathrm{P}<0.001)$, C3 ( $149 \pm 5.09$ vs $108 \pm 5.68 \mathrm{mg} / \mathrm{dl} ; \mathrm{P}<0.001)$, Fibrinogen $(324 \pm 35.78$ vs $250 \pm 10.83 \mathrm{mg} / \mathrm{dl} ; \mathrm{P}<0.001)$, Ferritin $(289 \pm 6.16$ vs $145 \pm 23.09$ $\mathrm{ng} / \mathrm{ml} ; \mathrm{P}<0.001)$, ESR $(20 \pm 3.25$ vs $8 \pm 1.04 \mathrm{~mm} 3 / \mathrm{hr} ; \mathrm{P}<0.001)$, ALT ( $47 \pm 3.97$ vs $25 \pm 5.80 \mathrm{U} / \mathrm{L} ; \mathrm{P}<0.001)$ and AST $(70 \pm 15.83$ vs $25 \pm 6.12 \mathrm{U} / \mathrm{L} ; \mathrm{P}<0.001)$. These results indicate that hyperuricemia association elevated inflammatory biomarker and liver enzymes studied.

Table 1: Distribution of inflammatory biomarker and liver enzymes among cases and controls.

\begin{tabular}{|c|c|c|c|}
\hline Variables & Case(n=70) Mean \pm SD & Control (n=70) Mean \pm SD & \% Different \\
\hline CRP (mg/dl) & $7 \pm 1.81$ & $4 \pm 0.94$ & 54.55 \\
\hline C3 (mg/dl) & $149 \pm 5.09$ & $108 \pm 5.68$ & 31.91 \\
\hline Fibrinogen (mg/dl) & $324 \pm 35.78$ & $250 \pm 10.83$ & 25.78 \\
\hline Ferritin (ng/ml) & $289 \pm 6.16$ & $145 \pm 23.09$ & 6.001 \\
\hline ESR (mm/hr) & $20 \pm 3.25$ & $8 \pm 1.04$ & 0.001 \\
\hline ALT (U/L) & $47 \pm 3.97$ & $25 \pm 5.80$ & 0.001 \\
\hline AST (U/L) & $70 \pm 15.83$ & $25 \pm 6.12$ & 61.11 \\
\hline
\end{tabular}




\section{Correlation between uric acid and inflammatory biomarker and liver enzymes among the study population}

The Table 2 showed that Relation of uric acid with inflammatory biomarker and liver enzymes among the study population. Pearson correlation showed that that a positive significant correlation between uric acid and CRP $(\mathrm{r}=0.656, \mathrm{P}<0.001)$, Fibrinogen $(\mathrm{r}=$ $0.784, \mathrm{P}<0.001)$, Ferritin $(\mathrm{r}=0.939, \mathrm{P}<0.001)$, ESR $(\mathrm{r}=0.89, \mathrm{P}<$ 0.001), ALT ( $\mathrm{r}=0.886, \mathrm{P}<0.001)$, AST $(\mathrm{r}=0.844, \mathrm{P}<0.001)$.

Table 2: Correlation between uric acid and inflammatory biomarker and liver enzymes among the study population.

\begin{tabular}{|c|c|c|}
\hline \multirow{2}{*}{ Biomarker } & \multicolumn{2}{|c|}{ Uric acid (mg/d) } \\
\cline { 2 - 3 } & $\mathbf{r}$ & P-value \\
\hline CRP $(\mathrm{mg} / \mathrm{dl})$ & 0.656 & $<0.001$ \\
\hline Fibrinogen $(\mathrm{mg} / \mathrm{dl})$ & 0.784 & $<0.001$ \\
\hline Ferritin (ng/ml) & 0.939 & $<0.001$ \\
\hline ESR (mm/hr) & 0.89 & $<0.001$ \\
\hline ALT (U/L) & 0.886 & $<0.001$ \\
\hline AST (U/L) & 0.844 & $<0.001$ \\
\hline
\end{tabular}

\section{Discussion}

Elevated uric acid has long been associated with several complications [16]. Newly studies of the pathological mechanism of gout disease illustrated that hyperuricemia associated with insight into the underlying mechanisms of monosodium urate crystals induce an inflammatory reaction involved in the pathology of gout by the deposition of monosodium urate crystals within joints and connective tissue engenders highly inflammatory but localized responses [17]. In our findings observed that means of Inflammatory markers such as ESR, CRP, ferritin, fibrinogen, and C3 were higher in the cases when compared to control also positive relationship for these parameters. Our study agreed with the previous study found that correlation between serum C-reactive protein and uric acid levels in a German population-based survey [18] and positive and significant association between uric acid and inflammatory markers such as C-reactive protein [19]. Also, our results agreed with the previous study reported that a positive relationship between serum uric acid and acute-phase reactants, such as high-sensitivity CRP, fibrinogen, ferritin, complement C3, and erythrocyte sedimentation rate [20]. Regarding the association between hyperuricemia and liver profile, the results showed ALT and AST was significantly higher in hyperuricemia patients compared to that of control and positive correlation between liver function test and elevated uric acid.

These findings are parallel to the previous study showed that participants with hyperuricemia were more likely to have metabolic disorders and elevated ALT [21,22]. this means a positive association between hyperuricemia and elevated ALT were also reported by Chen et al. [23]. However, Lee et al. reported that an increase in uric acid was an independent risk factor for elevated ALT [24]. In China, a large sample of employees (8925 participants) showed that hyperuricemia was associated with NAFLD [22]. Another study among obese adolescents found a significant association between hyperuricemia and elevated ALT [25]. Moreover, Afzali A et al. supported the association between elevated uric acid and the increased prevalence of the chronic liver disease in a prospective study [21,26-28]. One potential mechanism might be responsible for the positive association between increased uric acid and elevated ALT such as Hyperuricemia and NAFLD [29]. In another study conducted by Zelber-Sagi et al. showed that uric acid was independently associated with elevated liver enzymess [30].

\section{Conclusion}

The present study showed a strong association between uric acid and development of inflammatory disease among Gazan patients. Early prevention of hyperuricemia can reduce the incidence of hyperuricemia complication among Gazan patients with reducing liver disease. Moreover, elevated uric acid may be used as a predictor in inflammatory disorders.

\section{Acknowledgement}

None.

\section{Conflict of Interest}

No conflicts of interest.

\section{References}

1. Billiet L, Doaty S, Katz JD, Velasquez MT (2014) Review of hyperuricemia as new marker for metabolic syndrome. ISRN rheumatology.

2. Wortmann RL (2002) Gout and hyperuricemia. Current opinion in rheumatology 14: 281-286.

3. Zhang L, Wan Q, Zhou Y, Xu J, Yan C, et al. (2019) Age-related and genderstratified differences in the association between high triglyceride and risk of hyperuricemia. Lipids Health Dis 18(1): 147.

4. Wang P, Smith SE, Garg R, Lu F, Wohlfahrt A et al. (2018) Identification of monosodium urate crystal deposits in patients with asymptomatic hyperuricemia using dual-energy CT. RMD Open 4(1): e000593.

5. Elsous A, Radwan M, Al Sharif H, Abu Mustafa A (2017) Medications adherence and associated factors among patients with type 2 diabetes mellitus in the Gaza Strip, Palestine. Front Endocrinol (Lausanne) 8: 100.

6. Li M, Hu X, Fan Y, Li K, Zhang X, et al. (2016) Hyperuricemia and the risk for coronary heart disease morbidity and mortality a systematic review and dose-response meta-analysis. Sci Rep 6: 19520.

7. Radwan M, Elsous A, Al Sharif H, Abu Mustafa A (2018) Glycemic control among primary care patients with type 2 diabetes mellitus in the Gaza Strip, Palestine. Ther Adv Endocrinol Metab 9(1): 3-14.

8. Fathy SA, Abdel Hamid FF, Zabut BM, Jamee AF, Ali MA et al. (2015) Diagnostic utility of BNP, corin and furin as biomarkers for cardiovascular complications in type 2 diabetes mellitus patients. Biomarkers 20(6-7): 460-469.

9. Jin M, Yang F, Yang I, Yin Y, Luo JJ, et al. (2012) Uric acid, hyperuricemia and vascular diseases. Front Biosci (Landmark Ed) 17: 656-669.

10. Kuwabara M (2015) Hyperuricemia, cardiovascular disease, and hypertension. Pulse (Basel) 3(3-4): 242-252.

11. Zhang S, Wang Y, Cheng J, Huangfu N, Zhao R, et al. (2019) Hyperuricemia and Cardiovascular Disease, Current pharmaceutical design. Curr Pharm Des 25(6): 700-709.

12. Isaka Y, Takabatake Y, Takahashi A, Saitoh T, Yoshimori T (2016) Hyperuricemia-induced inflammasome and kidney diseases. Nephrology Dialysis Transplantation 31(6): 890-896.

13. Siimes MA, Addiego JE, Dallman PR (1974) Ferritin in serum: diagnosis of iron deficiency and iron overload in infants and children. Blood 43(4): 581-590. 
14. Conen D, Wietlisbach V, Bovet P, Shamlaye C, Riesen W, et al. (2004) Prevalence of hyperuricemia and relation of serum uric acid with cardiovascular risk factors in a developing country. BMC Public Health 4: 9 .

15. Hayashi H, Lo Grippo G (1972) C-reactive protein: Potential significance of quantitation in patients with chronic diseases. Henry Ford Hosp Med J 20: 91-96.

16. Chaloemwong J, Tantiworawit A, Rattanathammethee T, Chai Adisaksopha C, Rattarittamrong E, et al. (2019) Hyperuricemia, urine uric excretion, and associated complications in thalassemia patients. Ann Hematol 98(5): 1101-1110.

17. Martillo MA, Nazzal L, Crittenden DB (2014) The crystallization of monosodium urate, Current rheumatology reports 16(2): 400.

18. Fröhlich M, Imhof A, Berg G, Hutchinson WL, Pepys MB, et al. (2000) Association between C-reactive protein and features of the metabolic syndrome: a population-based study. Diabetes care 23(12): 1835-1839.

19. Ruggiero C, Cherubini A, Ble A, Bos AJ, Maggio M, et al. (2006) Uric acid and inflammatory markers. Eur Heart J 27(10): 1174-1181.

20. Spiga R, Marini MA, Mancuso E, Di Fatta C, Fuoco A, et al. (2017) Uric acid is associated with inflammatory biomarkers and induces inflammation via activating the NF- $\kappa$ B signaling pathway in HepG2 cells. Arterioscler Thromb Vasc Biol 37(6): 1241-1249.

21. AbuMustafa AM (2017) clinical and Biochemical associations with Diabetic retinopathy in Male Patients in the Gaza strip. Front Endocrinol (Lausanne) 8: 302 .

22. Xu C, Yu C, Xu L, Miao M, Li Y (2010) High serum uric acid increases the risk for nonalcoholic Fatty liver disease: a prospective observational study. PLoS One 5(7): e11578.
23. Chen S, Guo X, Yu S, Sun G, Yang H, et al. (2016) Association between Serum Uric Acid and Elevated Alanine Aminotransferase in the General Population. Int J Environ Res Public Health 13(9): E841.

24. Lee YJ, Lee HR, Lee JH, Shin YH, Shim JY (2010) Association between serum uric acid and non-alcoholic fatty liver disease in Korean adults. Clin Chem Lab Med 48(2): 175-180.

25. Chen SCC, Huang YF, Der Wang J (2012) Hyperferritinemia and hyperuricemia may be associated with liver function abnormality in obese adolescents. PLoS One 7(10): e48645.

26. Afzali A, Weiss NS, Boyko EJ, Ioannou GN (2010) Association between serum uric acid level and chronic liver disease in the United States. Hepatology 52(2): 578-589.

27. El Khair M, AbuMustafa A, Zabut B (2019) Clinical and Dietary Assessment of Poor Glycemic Control Among Type 2 Diabetic Patients in Gaza Strip, Palestine. J Dia Endo Meta: JDEM-104.

28. AbuMustafa A, Yassin MM (2017) Clinical and biochemical aspects associated with diabetic nephropathy among type 2 diabetic males in Gaza strip.

29. Angelico F, Del Ben M, Conti R, Francioso S, Feole K, et al. (2005) Insulin resistance, the metabolic syndrome, and nonalcoholic fatty liver disease. J Clin Endocrinol Metab 90(3): 1578-1582.

30. Zelber Sagi S, Ben Assuli O, Rabinowich L, Goldstein A, Magid A, et al. (2015) The association between the serum levels of uric acid and alanine aminotransferase in a population-based cohort. Liver Int 35(11): 24082415 . 